\title{
Long noncoding RNAAFAPI-ASI, a potential novel biomarker to predict the clinical outcome of cancer patients: a meta-analysis
}

This article was published in the following Dove Press journal:

OncoTargets and Therapy

12 July 2016

Number of times this article has been viewed

\author{
Fang-teng Liu',* \\ Qi-zhen Xue ${ }^{2, *}$ \\ Pei-qian Zhu' \\ Hong-liang Luo' \\ Yi Zhang' \\ Tengfei Hao' \\ 'Department of Gastrointestinal \\ Surgery, the Second Affiliated \\ Hospital of Nanchang University, \\ Nanchang, Jiangxi Province, ${ }^{2}$ Institute \\ of Toxicology, College of Preventive \\ Medicine, Third Military Medical \\ University, Chongqing, People's \\ Republic of China \\ *These authors contributed equally \\ to this paper
}

\begin{abstract}
A number of studies have demonstrated that the expression level of actin filamentassociated protein 1 antisense RNA 1 (AFAP1-AS1) was upregulated in various cancers. High expression of AFAP1-AS1 is associated with an increased risk of metastasis and a poor prognosis in cancer patients. The electronic search was conducted in PubMed, EMBASE, Cochrane Library, China National Knowledge Infrastructure, and Wanfang database. We collected relevant articles to explore the association between the expression levels of AFAP1-AS1 and lymph node metastasis, distant metastasis, overall survival, relapse-free survival, and progression-free survival. A total of 1,017 patients from eight studies were finally included. The results showed that cancer patients with high AFAP1-AS1 expression suffered an increased risk of developing lymph node metastasis (odds ratio $=3.19,95 \%$ confidence interval $[\mathrm{CI}]: 2.11-4.83, P<0.00001$ ) and distant metastasis (odds ratio $=3.05,95 \% \mathrm{CI}$ : 1.84-5.04, $P<0.0001$ ). Moreover, we found that patients with high AFAP1-AS1 expression also had a poorer overall survival (hazard ratio [HR]: 1.98, 95\% CI: 1.57-2.38, $P=0.000$ ), a worse progression-free survival (HR: $1.73,95 \%$ CI: $1.11-2.35, P=0.000$ ), and a shorter recurrence-free survival (HR: 1.96, 95\% CI: 1.02-2.90, $P=0.000)$ than those with low AFAP1-AS1 expression. High expression of AFAP1-AS1 was associated with poor clinical outcome. AFAP1-AS1 might serve as a potential novel biomarker for indicating the clinical outcomes in human cancers.
\end{abstract}

Keywords: lncRNA, AFAP1-AS1, carcinoma, clinical outcome, meta-analysis

\section{Introduction}

Long noncoding RNAs (IncRNAs) are nonprotein-coding transcripts with length $>200$ nucleotides. ${ }^{1,2}$ They have been dismissed as transcriptional "noise" in the past decades, but nowadays they are regarded as rising stars in the field of cancer therapy and prediction. ${ }^{3-5}$ Much more attention has been paid to lncRNAs. Accumulating evidence has shown that lncRNAs can participate in a wide range of physiological processes, and they could regulate gene transcription at the transcriptional, posttranscriptional, and epigenetic levels. ${ }^{6-8}$ The dysregulation of 1 ncRNAs has been reported to play a vital role in diverse human diseases, especially in cancers, ${ }^{9-12}$ the dysregulation of lncRNAs are associated with tumor initiation, progression, and metastasis.

Among all lncRNAs, actin filament-associated protein 1 antisense RNA 1 (AFAP1AS1) is a newly identified lncRNA, which has attracted widespread attention recently. Dysregulated expression of AFAP1-AS1 has been reported in various human cancers, including esophageal adenocarcinoma, ${ }^{13}$ pancreatic carcinoma, ${ }^{14}$ and lung cancer. ${ }^{15}$ Abnormal expression of AFAP1-AS1 was involved in human carcinogenesis. AFAP1AS1 expressed at high levels in cancerous tissue was reported to be associated

\footnotetext{
Correspondence: Pei-qian Zhu;

Hong-liang Luo

Department of Gastrointestinal Surgery, the Second Affiliated Hospital of Nanchang University, I Minde Road, Nanchang 330000, Jiangxi Province, People's Republic of China Tel +86 I380353 5660; +86 I309728000 I Email zhupeiqian@।63.com; 517295653@qq.com
} 
with metastasis and prognosis in various kinds of cancer. Therefore, AFAP1-AS1 might be feasible as a diagnostic biomarker and prognostic factor. This current meta-analysis was performed to explore the correlation of AFAP1-AS1 with clinical outcome of cancer patients, to further determine whether AFAP1-AS1 could serve as an effective biomarker for metastasis and prognosis.

\section{Methods}

\section{Literature search strategies}

We conducted a comprehensive search in PubMed, EMBASE, Cochrane Library, China National Knowledge Infrastructure, and Wanfang database. We based our dates for literature retrieval from January 1, 1988 to February 10, 2016. There was no language restriction. The keywords for the search were as follows: "long non-coding RNA AFAP1-AS1" or "IncRNA AFAP1-AS1" or "AFAP1-AS1" or "AFAP1 antisense RNA 1" or "actin filament associated protein 1 antisense RNA1". Besides, in order to get potentially eligible papers, we got additional relevant articles by manually viewing the reference lists.

\section{Inclusion and exclusion criteria}

Inclusion criteria were the following: 1) articles investigating the role of AFAP1-AS1 in the development of human cancer, 2) the expression levels of AFAP1-AS1 in primary cancerous tissue were measured, and 3 ) patients were divided into high and low groups based on the expression levels of AFAP1-AS1.

Exclusion criteria were the following: 1) studies without usable data, 2) duplicate publications, and 3) reviews, letters, case reports, and expert opinions.

\section{Date extraction and quality assessment}

The information was individually extracted from each included studies by two investigators (YZ and TFH). The information and data are listed as following: name of first author, year of publication, country, ethnicity, cancer type, total number of patients, number of high AFAP1-AS1 expression group and low AFAP1-AS1 expression group, number of patients with lymph node metastasis (LNM) and distant metastasis (DM) in each group, outcome measures, the assessment methods, the criteria of high expression. If there were disagreements, a consensus was reached by the third investigator (QZX). The Newcastle-Ottawa Scale (NOS) was applied to assess the quality of all included studies. The NOS score ranged between 0 and 9 , and a study with an NOS score $\geq 6$ was considered to be of high quality.

\section{Statistical methods}

This meta-analysis was conducted by using Review Manager 5.3 software (Cochrane network) and Stata SE12.0 (StataCorp, College Station, TX, USA). The heterogeneity among studies was determined by using the chi-square-based $Q$ test and $I^{2}$ statistics, ${ }^{16}$ a $P$-value for $Q$ test $<0.05$, and $I^{2}$ value $>50 \%$ were all considered as significant heterogeneity. If there was a significant heterogeneity across studies $\left(P_{\mathrm{Q}} \leq 0.05\right.$, $I^{2} \geq 50 \%$ ), we chose the random-effects model, ${ }^{17}$ if no severe heterogeneity was observed between studies $\left(P_{Q}>0.05\right.$, $I^{2}<50 \%$ ), the fixed-effects model was adopted. ${ }^{18}$ The $P$-value $<0.05$ was considered to be statistically significant.

For the statistical analysis of hazard ratios (HRs), the steps of analysis were as follows: first, the data were directly extracted from article if available. If not, the data were extracted with Engauge Digitizer version 4.1 (http:// digitizer.sourceforge.net/, a free downloaded software) from Kaplan-Meier curves. Second, the data pending analysis was input in Stata SE12.0. For the data with severe heterogeneity $\left(P_{\mathrm{Q}} \leq 0.05, I^{2} \geq 50 \%\right)$, the combination result was obtained with "metan hr lci uci, label (namevar = study) random effect ("HR") textsize (180)". For the data without severe heterogeneity $\left(P_{\mathrm{Q}}>0.05, I^{2}<50 \%\right)$, combination result was obtained with "metan hr lci uci, label (namevar = study) fixed effect ("HR") textsize (180)". Hereinto, hr = hazard ratio, lci = lower confidence intervals; uci = upper confidence intervals; textsize (180) indicated an adjustable text size in the input image. Third, the result and image was extracted.

\section{Results \\ Studies characteristics}

Figure 1 shows the detailed process of literature retrieval. Finally, a total of seven articles (eight studies) were included in this meta-analysis. ${ }^{14,15,19-23}$ There were a total of 1,017 cancer patients, the mean patient sample size was 127.1 (range 78-226). All included studies came from People's Republic of China. Five different types of cancer were evaluated in the meta-analysis, with three cases of lung cancer, one case of pancreatic ductal adenocarcinoma, one case of esophageal squamous cell carcinoma, one case of nasopharyngeal carcinoma, and two cases of hepatocellular carcinoma. In these included studies, the level of AFAP1-AS1 expression was determined in collected tumor tissues. The negative control was adjacent noncancerous tissues and healthy tissues. The main characteristics are summarized in Table 1. And these studies were evaluated to be of high quality. 


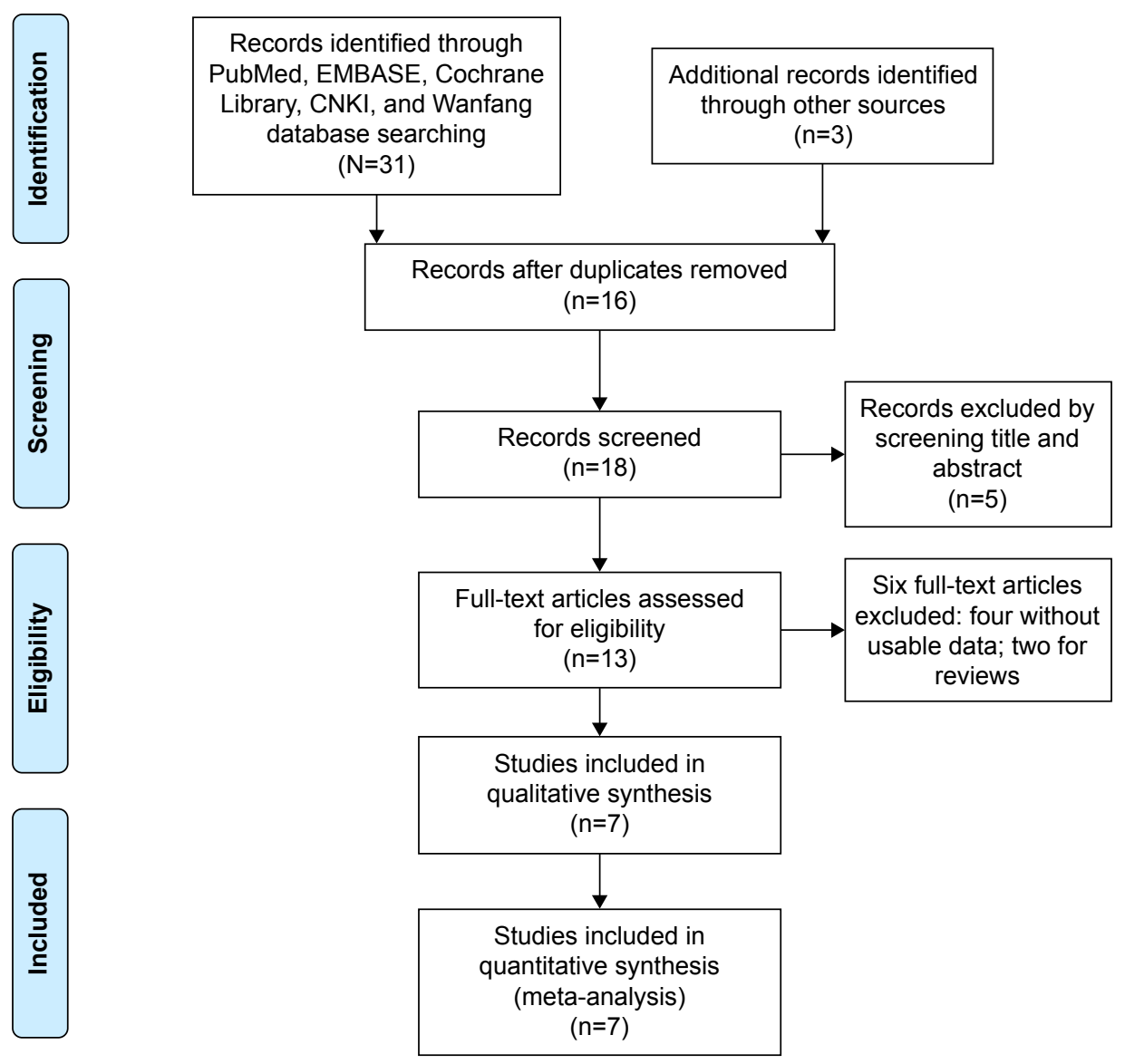

Figure I Flowchart presenting the steps of literature search and selection. Abbreviation: CNKI, China National Knowledge Infrastructure.

\section{The association between IncRNA AFAPI-ASI and metastasis}

\section{Association between IncRNA AFAPI-ASI and LNM}

Four studies reported the number of patients according to AFAP1-AS1 expression levels in a total of 451 cancer patients. There was no severe heterogeneity among studies $\left(I^{2}=0 \%, P_{\mathrm{Q}}=0.50\right)$, then the fixed-effects model was applied to calculate the data. The odds ratio (OR) expressed as high AFAP1-AS1 expression group versus low expression group, was 3.19 (95\% confidence interval [CI]: 2.11-4.83, $P<0.00001$ ) (Figure 2). From the analysis results, we found that compared with low AFAP1-AS1 expression group, a significant elevated LNM rate was observed in high AFAP1AS1 expression group.

\section{Association between IncRNA AFAPI-ASI and DM}

Three studies reported the number of patients with DM. There was no severe heterogeneity across studies $\left(I^{2}=7 \%\right.$, $\left.P_{\mathrm{Q}}=0.34\right)$, and the fixed-effects model was adopted. The result showed that patients with high AFAP1-AS1 expression in tumor tissues may have an increased risk of developing DM (OR: 3.05, 95\% CI: 1.84-5.04, $P<0.0001$ ) (Figure 3).

\section{The association between IncRNA} AFAPI-ASI and prognosis

Association between IncRNA AFAPI-ASI and overall survival

All included studies reported the overall survival (OS) according to AFAP1-AS1 expression levels in a total of 1,017 patients. Due to no significant heterogeneity $\left(I^{2}=0 \%\right.$, $\left.P_{\mathrm{Q}}=0.853\right)$, the fixed-effects model was chosen to estimate the pooled HRs with corresponding 95\% CIs. The HR, expressed as high AFAP1-AS1 expression group versus low expression group, was 1.98 (95\% CI: 1.57-2.38, $P=0.000)$ (Figure 4). When comparing the OS of cancer patients between the two groups, we found that there was a significant difference in the OS. Compared with low AFAP1-AS1 expression group, high AFAP1-AS1 expression group had a statistically significant reduced OS. The cancer patients with high AFAP1-AS1 expression might be correlated with shorter OS. 


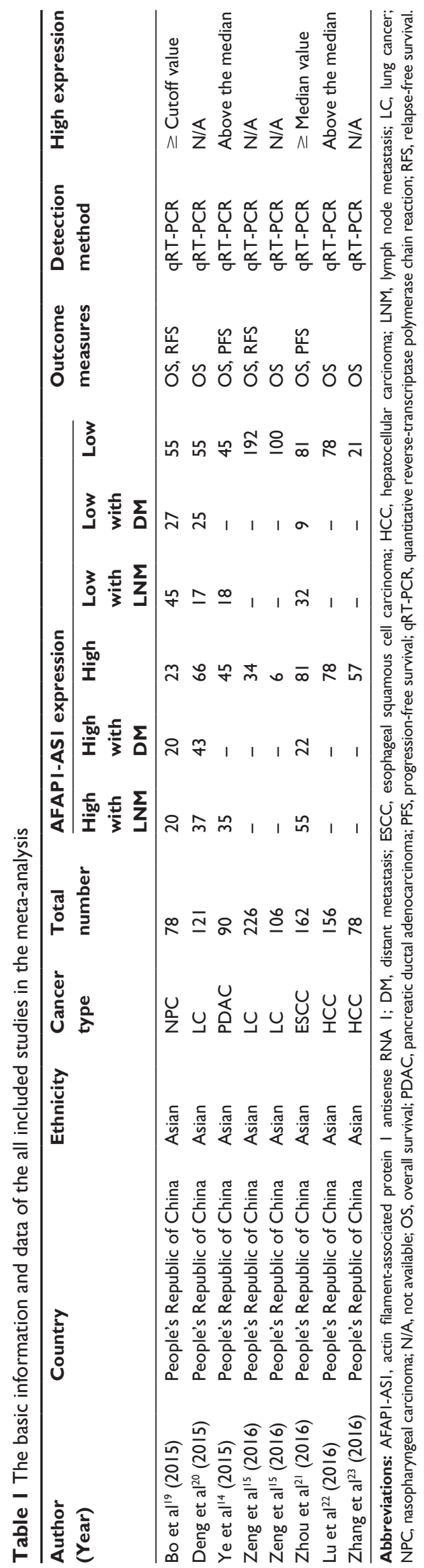

Association between IncRNA AFAPI-ASI and recurrence-free survival

Two studies reported the recurrence-free survival (RFS) according to AFAP1-AS1 expression levels. No significant heterogeneity was observed between studies $\left(P^{2}=0 \%, P_{\mathrm{Q}}=0.875\right)$, the fixed-effects model was applied to estimate the pooled HRs with corresponding 95\% CIs. Overall, we found a shorter RFS in the cancer patients with elevated AFAP1-AS1 expression (HR: 1.96, 95\% CI: 1.02-2.90, $P=0.000$ ) (Figure 5).

\section{Association between IncRNA AFAPI-ASI and progression-free survival}

Two studies reported the progression-free survival (PFS) according to AFAP1-AS1 expression levels. Because of no significant heterogeneity across studies $\left(I^{2}=0 \%, P_{\mathrm{Q}}=0.592\right)$, the fixed-effects model was applied to calculate the pooled HRs and the associated $95 \%$ CIs. Overall, the analysis result indicated that PFS was significantly worse in patients with high AFAP1-AS1 expression in tumor tissues (HR: 1.73, 95\% CI: 1.11-2.35, $P=0.000$ ) (Figure 6).

\section{Sensitivity analysis}

For meta-analysis of the association between AFAP1-AS1 and OS, sensitivity analysis was conducted by deleting each study in turn from the pooled analysis to examine the influence of the removed data set to the overall HRs. Exclusion of each study did not influence the result, suggesting that the result of synthetic analysis was robust.

\section{Publication bias}

For meta-analysis of the association between AFAP1-AS1 and OS, Begg's funnel plot with pseudo 95\% CIs was provided (Figure 7). There was no significant publication bias observed across studies. Publication bias was assessed statistically using the Begg's test and Egger's test. Still, the results of Begg's test $(\operatorname{Pr}>|z|=0.083)$ revealed no publication bias $(P>0.05)$, and the results of Egger's test $(P>|t|=0.235$, 95\% CI: -1.266 to 4.240 ) also showed no publication bias.

\section{Discussion}

In recent years, lncRNA has become a rising star in the noncoding RNA. More than thousands of lncRNAs have been detected and reported, such as HOTAIR, ${ }^{24}$ MALAT $1,{ }^{25}$ and PCAT- $1 .{ }^{26}$ Aberrant expressions of lncRNAs have been found in tumor tissues, and are involved in the onset and progression of cancer. lncRNAs could act as oncogenic and tumor suppressor roles in tumorigenesis. For example, lncRNA-UCA1 was reported to function as an oncogene 


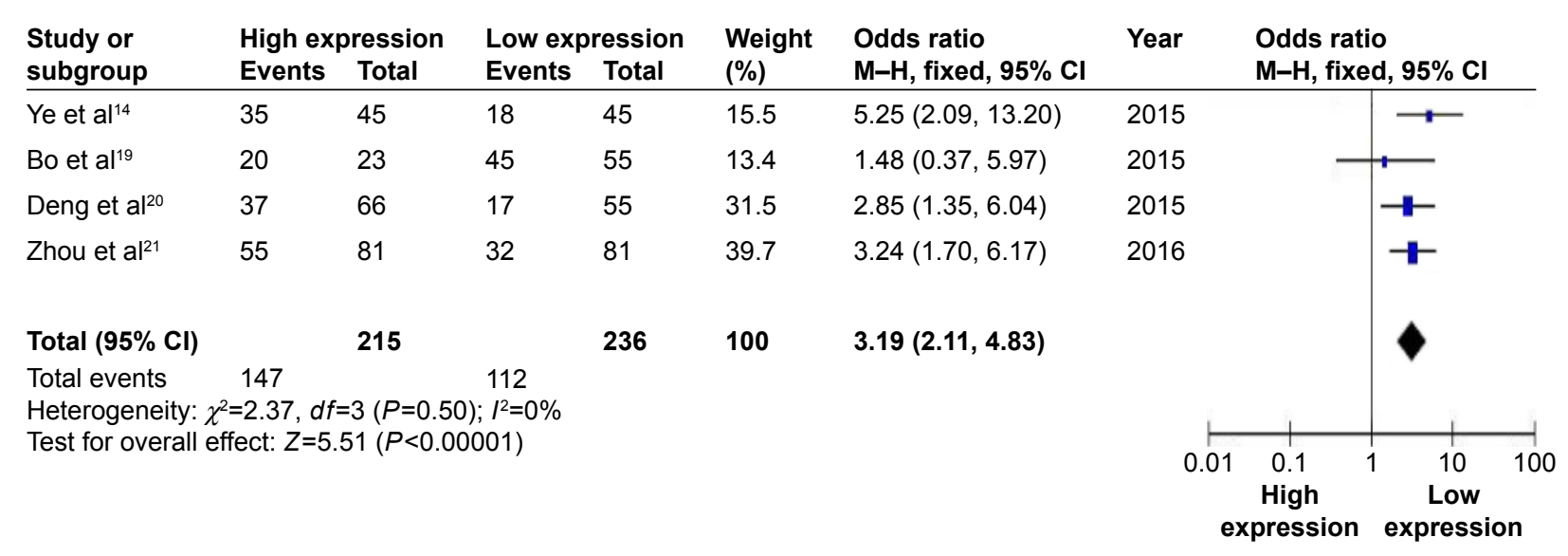

Figure 2 Forest plot for the association between AFAPI-ASI expression levels with LNM.

Abbreviations: AFAPI-ASI, actin filament-associated protein I antisense RNA I; Cl, confidence interval; LNM, lymph node metastasis; M-H, Mantel-Haenszel test.

\begin{tabular}{|c|c|c|c|c|c|c|c|c|c|c|}
\hline \multirow{2}{*}{$\begin{array}{l}\begin{array}{l}\text { Study or } \\
\text { subgroup }\end{array} \\
\text { Bo et al }{ }^{19}\end{array}$} & \multicolumn{2}{|c|}{$\begin{array}{l}\text { High expression } \\
\text { Events Total }\end{array}$} & \multicolumn{2}{|c|}{$\begin{array}{l}\text { Low expression } \\
\text { Events Total }\end{array}$} & \multirow{2}{*}{$\begin{array}{l}\text { Weight } \\
\text { (\%) }\end{array}$} & \multirow{2}{*}{$\begin{array}{l}\begin{array}{l}\text { Odds ratio } \\
\text { M-H, fixed, } 95 \% \text { Cl }\end{array} \\
6.91(1.84,25.97)\end{array}$} & Year & \multicolumn{3}{|c|}{$\begin{array}{l}\text { Odds ratio } \\
\mathrm{M}-\mathrm{H} \text {, fixed, } 95 \% \mathrm{Cl}\end{array}$} \\
\hline & 20 & 23 & 27 & 55 & & & 2015 & & 1 & \\
\hline Deng et $\mathrm{al}^{20}$ & 43 & 66 & 25 & 55 & 52.4 & $2.24(1.08,4.67)$ & 2015 & & & \\
\hline Zhou et $\mathrm{al}^{21}$ & 22 & 81 & 9 & 81 & 36.1 & $2.98(1.28,6.97)$ & 2016 & & - & \\
\hline Total $(95 \% \mathrm{Cl})$ & & 170 & & 191 & 100 & $3.05(1.84,5.04)$ & & & & \\
\hline \multicolumn{11}{|c|}{$\begin{array}{l}\text { Total events } \quad 85 \\
\text { Heterogeneity: } \chi^{2}=2.14, d f=2(P=0.34) ; I^{2}=7 \% \\
\text { Test for overall effect: } Z=4.33(P<0.0001)\end{array}$} \\
\hline & & & & & & & 0.01 & $\begin{array}{l}0.1 \\
\text { High } \\
\text { xpression }\end{array}$ & $\begin{array}{cc}1 & 10 \\
\text { Low } \\
\text { expressi }\end{array}$ & 100 \\
\hline
\end{tabular}

Figure 3 Forest plot for the association between AFAPI-ASI expression levels with DM.

Abbreviations: AFAPI-ASI, actin filament-associated protein I antisense RNA I; Cl, confidence interval; DM, distant metastasis; M-H, Mantel-Haenszel test.

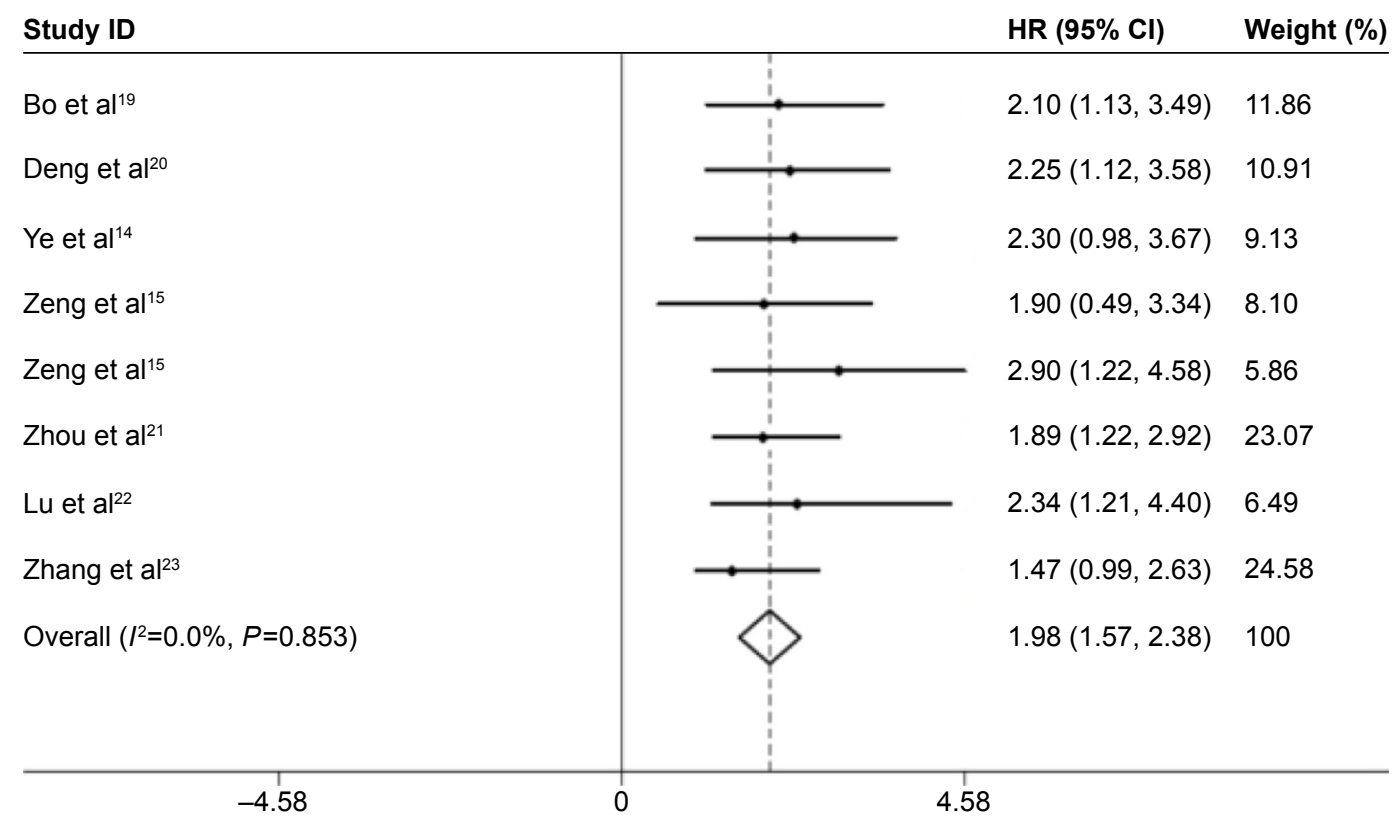

Figure 4 Meta-analysis of the pooled HRs of OS.

Abbreviations: $\mathrm{Cl}$, confidence interval; $\mathrm{HR}$, hazard ratio; OS, overall survival. 


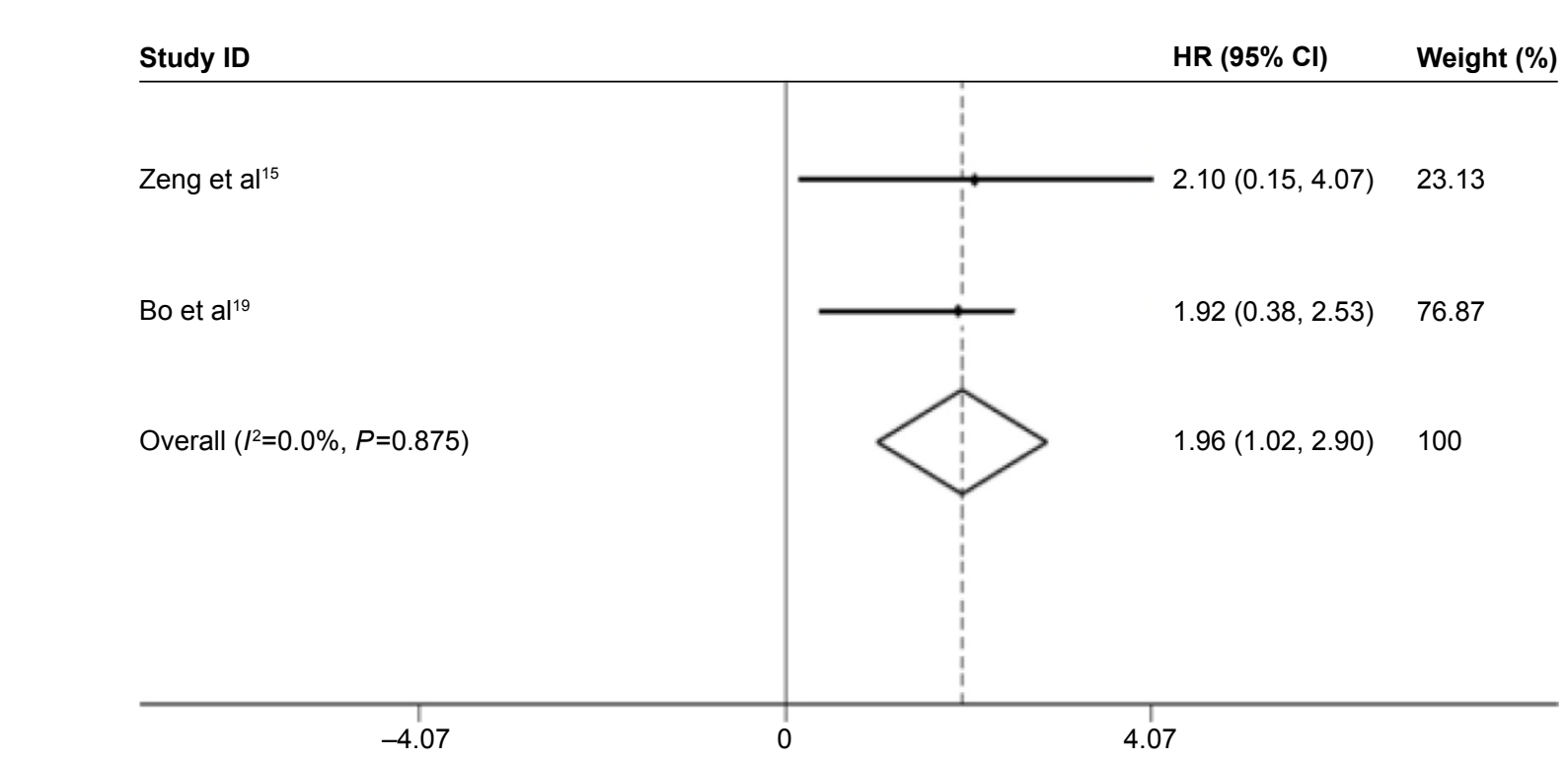

Figure 5 Meta-analysis of the pooled HRs of RFS.

Abbreviations: $\mathrm{Cl}$, confidence interval; $\mathrm{HR}$, hazard ratio; RFS, relapse-free survival.

in non-small cell lung cancer ${ }^{27}$ and breast cancer ${ }^{28}$ and plasmacytoma variant translocation 1 (PVT1) has also been brought under the spotlight as the important oncogenes in cancer recently ${ }^{29}$ For GAS5, ${ }^{30}$ TUSC $7,{ }^{31}$ and ANRIL,,${ }^{32}$ they are all identified as pivotal tumor suppressor lncRNAs in human cancers. Growing number of studies have focused on relationship between IncRNAs and tumors, but the related mechanisms remain to be unclear.

AFAP1-AS1 is one of the lncRNAs located on the antisense strand of protein-coding gene AFAP1. AFAP1 is a kind of motor fiber-related protein, which acts as an adapter molecule to link to other proteins, such as SRC and PKC, to modulate changes in actin filament integrity, and to influence the cytophagy, cell movement, tumor invasion, and metastasis ${ }^{33-36}$ and the AFAP1-AS1 exon 2 and AFAP1 exons 14, 15, and 16 are just overlapping and complementary regions. ${ }^{19}$

Many researchers have reported that expression levels of AFAP1-AS1 in tumor tissues were significantly higher than in paired noncancerous tissues. AFAP1-AS1 might play the role of oncogenic lncRNA in cancer. Knocking

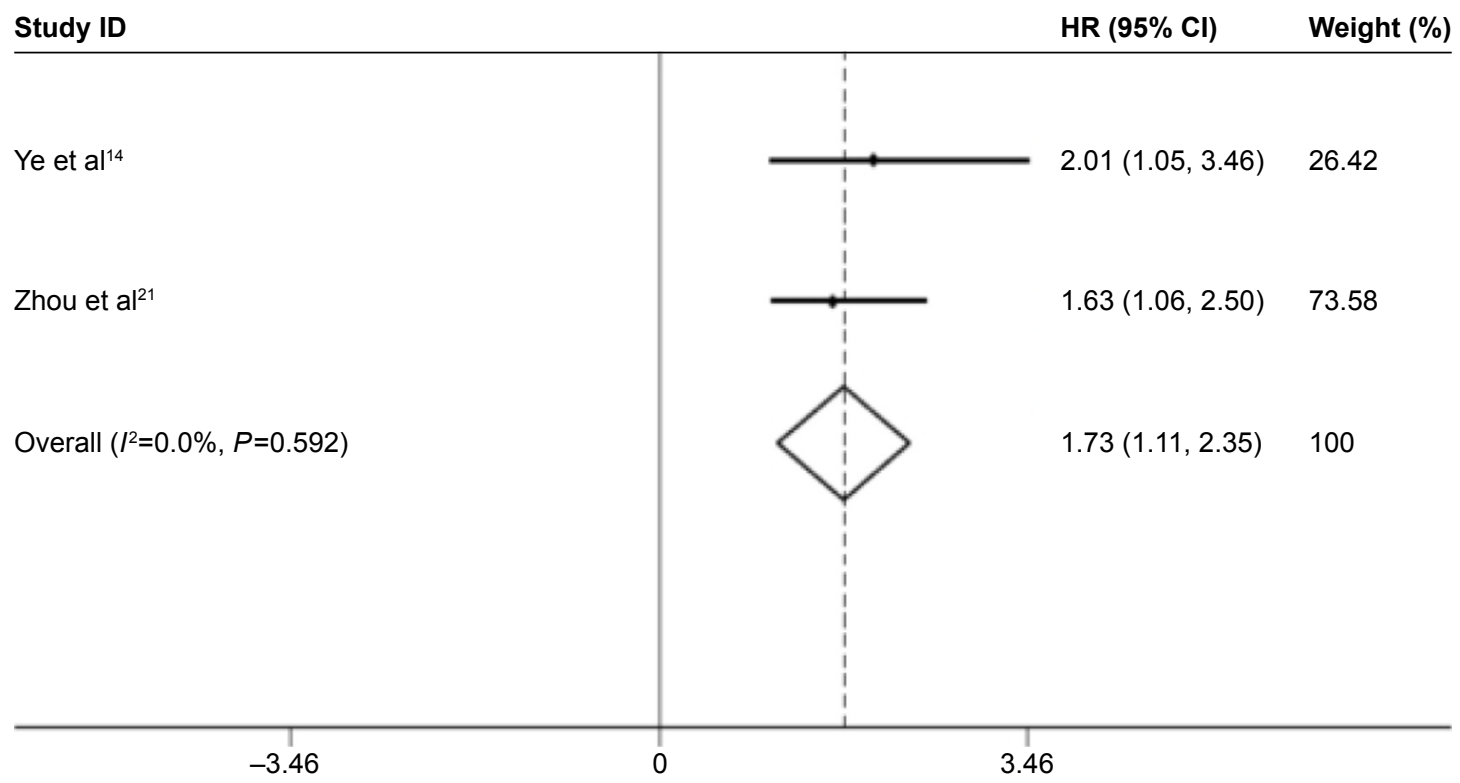

Figure 6 Meta-analysis of the pooled HRs of PFS.

Abbreviations: $\mathrm{Cl}$, confidence interval; $\mathrm{HR}$, hazard ratio; PFS, progression-free survival. 


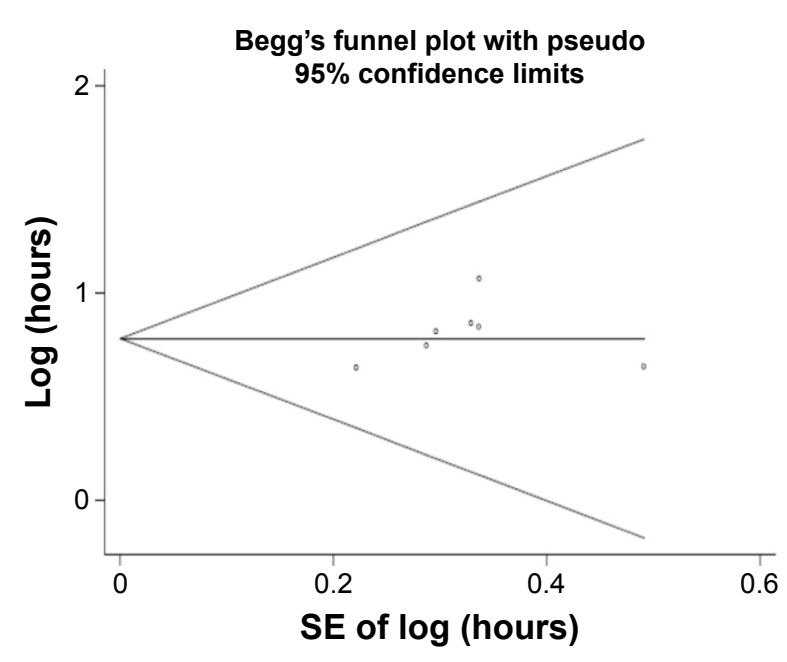

Figure 7 Funnel plot analysis of potential publication bias for OS. Abbreviations: OS, overall survival; SE, standard error.

down of AFAP1-AS1 could significantly inhibit the tumor cells, migration and invasive capability in vitro. On the contrary, cell proliferation, migration, and invasion could be enhanced by the expression of AFAP1-AS1. There was a close association between AFAP1-AS1 expression and tumor development and progression. Preliminary studies have suggested that AFAP1-AS1 could regulate the expression of AFAP1 gene, further affecting the Rho/Rac signaling pathway, inducing the regulation of cytoskeleton remodeling, thereby promoting tumor cell invasion and metastasis in lung cancer, ${ }^{15}$ nasopharyngeal carcinoma, ${ }^{19}$ and hepatocellular carcinoma. ${ }^{23}$ However, the specific molecular mechanism needs to be further investigated. Another study by $\mathrm{Lu}$ et $\mathrm{al}^{22}$ showed that cell proliferation and invasion in hepatocellular carcinoma would be promoted by AFAP1-AS1 through mediating related gene expression, such as $B C L-2$ and $\mathrm{Bax}$, which were well-known genes involved in cancer. ${ }^{37}$ In addition, AFAP1-AS1 was reported to be involved in chemoradiotherapy resistance, which might have predictive significance of definitive chemoradiotherapy response in esophageal squamous cell carcinoma. ${ }^{21}$ AFAP1-AS1 is one of the most intensely and frequently overexpressed lncRNAs in pancreatic ductal adenocarcinoma, ${ }^{14}$ and it has also been revealed that its overexpression was correlated with perineural invasion ${ }^{14}$ and poor disease-free survival. ${ }^{22}$

This meta-analysis we performed investigated the association of lncRNA-AFAP1-AS1 with metastasis (LNM, DM) and prognosis outcomes (OS, RFS, and PFS) in patients with cancer. From the available evidence, we found that there was a significant association between the expression levels of AFAP1-AS1 and metastasis and prognosis in various tumors. The patients with high AFAP1-AS1 expression might suffer higher probability of occurrence of LNM and DM. Furthermore, high expression was significantly correlated with a shorter OS and a poorer RFS and a worse PFS may be observed in the patients with high expression. And because there was no severe heterogeneity among studies and the limited number of studies included, sensitivity analysis and assessment of publication bias was not performed for LNM, DM, RFS, and PFS. The meta-analysis results indicated that lncRNA AFAP1-AS1 may act as a novel biomarker in predicting the clinical outcome of cancer patients.

\section{Study limitations}

First, the number of patients and types of cancers included was small. Second, studies included in the meta-analysis came from People's Republic of China, for this reason, the results we found may just represent the cases of Chinese patients with cancer. Third, because positive results could be published more easily than negative results, this may lead to larvaceous publication bias. Finally, there was a lack of a unified criterion for high expression. Therefore, more largerscale, multicenter, and high-quality studies are required to confirm our findings in the future.

\section{Disclosure}

The authors report no conflicts of interest in this work.

\section{References}

1. Mercer TR, Dinger ME, Mattick JS. Long non-coding RNAs: insights into functions. Nat Rev Genet. 2009;10(3):155-159.

2. Ponting CP, Oliver PL, Reik W. Evolution and functions of long noncoding RNAs. Cell. 2009;136(4):629-641.

3. Muers M. RNA: genome-wide views of long non-coding RNAs. Nat Rev Genet. 2011;12(11):742.

4. Yoon JH, Kim J, Gorospe M. Long noncoding RNA turnover. Biochimie. 2015;117:15-21.

5. Kung JT, Colognori D, Lee JT. Long noncoding RNAs: past, present, and future. Genetics. 2013;193:651-669.

6. Bergmann JH, Spector DL. Long non-coding RNAs: modulators of nuclear structure and function. Curr Opin Cell Biol. 2014;26:10-18.

7. Santosh B, Varshney A, Yadava PK. Non-coding RNAs: biological functions and applications. Cell Biochem Funct. 2015;33(1):14-22.

8. Bonasio R, Shiekhattar R. Regulation of transcription by long noncoding RNAs. Annu Rev Genet. 2014;48:433-455.

9. Li Y, Wang X. Role of long noncoding RNAs in malignant disease (Review). Mol Med Rep. 2016;13(2):1463-1469.

10. Kim J, Kim KM, Noh JH, Yoon JH, Abdelmohsen K, Gorospe M. Long noncoding RNAs in diseases of aging. Biochim Biophys Acta. 2016; 1859(1):209-221.

11. Lisitsyn NA, Chernyi AA, Karpov VL, Beresten SF. A role of long noncoding RNAs in carcinogenesis. Mol Biol (Mosk). 2015;49(4):561-570.

12. Liu Y, Sharma S, Watabe K. Roles of lncRNA in breast cancer. Front Biosci (Schol Ed). 2015;7:94-108.

13. Wu W, Bhagat TD, Yang X, et al. Hypomethylation of noncoding DNA regions and overexpression of the long noncoding RNA, AFAP1-AS1, in Barrett's esophagus and esophageal adenocarcinoma. Gastroenterology. 2013;144(5):956-966.e4. 
14. Ye Y, Chen J, Zhou Y, et al. High expression of AFAP1-AS1 is associated with poor survival and short-term recurrence in pancreatic ductal adenocarcinoma. J Transl Med. 2015;13:137.

15. Zeng Z, Bo H, Gong Z, et al. AFAP1-AS1, a long noncoding RNA upregulated in lung cancer and promotes invasion and metastasis. Tumour Biol. 2016;37(1):729-737.

16. Higgins JP, Thompson SG. Quantifying heterogeneity in a metaanalysis. Stat Med. 2002;21(11):1539-1558.

17. DerSimonian R, Laird N. Meta-analysis in clinical trials. Control Clin Trials. 1986;7:177-188.

18. Mantel N, Haenszel W. Statistical aspects of the analysis of data from retrospective studies of disease. J Natl Cancer Inst. 1959;22:719-748.

19. Bo H, Gong Z, Zhang W, et al. Upregulated long non-coding RNA AFAP1-AS1 expression is associated with progression and poor prognosis of nasopharyngeal carcinoma. Oncotarget. 2015;6(24): 20404-20418.

20. Deng J, Liang Y, Liu C, He S, Wang S. The upregulation of long noncoding RNA AFAP1-AS1 is associated with the poor prognosis of NSCLC patients. Biomed Pharmacother. 2015;75:8-11.

21. Zhou XL, Wang WW, Zhu WG, et al. High expression of long noncoding RNA AFAP1-AS1 predicts chemoradioresistance and poor prognosis in patients with esophageal squamous cell carcinoma treated with definitive chemoradiotherapy. Mol Carcinog. Epub 2016 Jan 12.

22. Lu X, Zhou C, Li R, et al. Critical role for the long non-coding RNA AFAP1-AS1 in the proliferation and metastasis of hepatocellular carcinoma. Tumour Biol. Epub 2016 Jan 23.

23. Zhang JY, Weng MZ, Song FB, et al. Long noncoding RNA AFAP1AS1 indicates a poor prognosis of hepatocellular carcinoma and promotes cell proliferation and invasion via upregulation of the RhoA/ Rac2 signaling. Int J Oncol. 2016;48(4):1590-1598.

24. Kim HJ, Lee DW, Yim GW, et al. Long non-coding RNA HOTAIR is associated with human cervical cancer progression. Int J Oncol. 2015; 46(2):521-530.

25. Cho SF, Chang YC, Chang CS, et al. MALAT1 long non-coding RNA is overexpressed in multiple myeloma and may serve as a marker to predict disease progression. BMC Cancer. 2014;14:809.
26. Ge X, Chen Y, Liao X, et al. Overexpression of long noncoding RNA PCAT-1 is a novel biomarker of poor prognosis in patients with colorectal cancer. Med Oncol. 2013;30(2):588.

27. Nie W, Ge HJ, Yang XQ, et al. LncRNA-UCA1 exerts oncogenic functions in non-small cell lung cancer by targeting miR-193a-3p. Cancer Lett. 2016;371(1):99-106.

28. Tuo YL, Li XM, Luo J. Long noncoding RNA UCA1 modulates breast cancer cell growth and apoptosis through decreasing tumor suppressive miR-143. Eur Rev Med Pharmacol Sci. 2015;19(18):3403-3411.

29. Colombo T, Farina L, Macino G, Paci P. PVT1: a rising star among oncogenic long noncoding RNAs. Biomed Res Int. 2015;2015:304208.

30. Ma C, Shi X, Zhu Q, et al. The growth arrest-specific transcript 5 (GAS5): a pivotal tumor suppressor long noncoding RNA in human cancers. Tumour Biol. 2016;37(2):1437-1444.

31. Cong M, Li J, Jing R, Li Z. Long non-coding RNA tumor suppressor candidate 7 functions as a tumor suppressor and inhibits proliferation in osteosarcoma. Tumour Biol. Epub 2016 Jan 19.

32. Li Z, Yu X, Shen J. ANRIL: a pivotal tumor suppressor long non-coding RNA in human cancers. Tumour Biol. Epub 2016 Jan 11.

33. Baisden JM, Gatesman AS, Cherezova L, Jiang BH, Flynn DC. The intrinsic ability of AFAP-110 to alter actin filament integrity is linked with its ability to also activate cellular tyrosine kinases. Oncogene. 2001;20(45):6607-6616.

34. Baisden JM, Qian Y, Zot HM, Flynn DC. The actin filament-associated protein AFAP-110 is an adaptor protein that modulates changes in actin filament integrity. Oncogene. 2001;20(44):6435-6447.

35. Gatesman A, Walker VG, Baisden JM, Weed SA, Flynn DC. Protein kinase $\mathrm{C}$ alpha activates c-Src and induces podosome formation via AFAP-110. Mol Cell Biol. 2004;24(17):7578-7597.

36. Clump DA, Yu JJ, Cho Y, et al. A polymorphic variant of AFAP-110 enhances cSrc activity. Transl Oncol. 2010;3(4):276-285.

37. Khan M, Maryam A, Qazi JI, Ma T. Targeting apoptosis and multiple signaling pathways with icariside II in cancer cells. Int J Biol Sci. 2015;11(9):1100-1112.
OncoTargets and Therapy

\section{Publish your work in this journal}

OncoTargets and Therapy is an international, peer-reviewed, open access journal focusing on the pathological basis of all cancers, potential targets for therapy and treatment protocols employed to improve the management of cancer patients. The journal also focuses on the impact of management programs and new therapeutic agents and protocols on

\section{Dovepress}

patient perspectives such as quality of life, adherence and satisfaction The manuscript management system is completely online and includes a very quick and fair peer-review system, which is all easy to use. Visit http://www.dovepress.com/testimonials.php to read real quotes from published authors. 